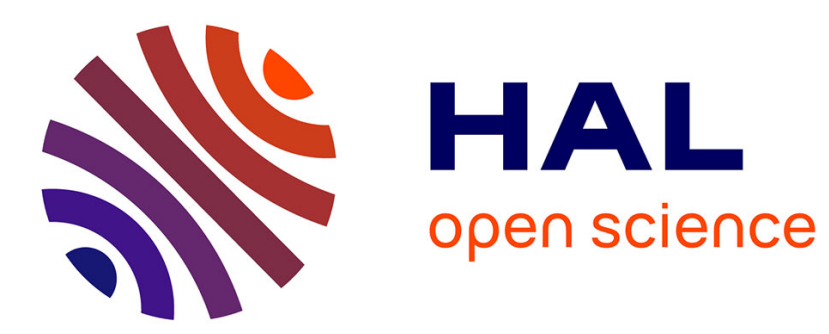

\title{
Primary resistance to antiretroviral drugs of HIV strains in Chad: a retrospective investigation by analysis of frozen dried blood spot samples
}

\author{
A Keita, N Djimera, O Djarma, Y N'guyen, T. Bourlet, L. Andreoletti
}

\section{- To cite this version:}

A Keita, N Djimera, O Djarma, Y N'guyen, T. Bourlet, et al.. Primary resistance to antiretroviral drugs of HIV strains in Chad: a retrospective investigation by analysis of frozen dried blood spot samples. European Journal of Clinical Microbiology and Infectious Diseases, 2020, 40, pp.1091 - 1095. 10.1007/s10096-020-04107-z . hal-03267073

\section{HAL Id: hal-03267073 https://hal.science/hal-03267073}

Submitted on 29 Jun 2021

HAL is a multi-disciplinary open access archive for the deposit and dissemination of scientific research documents, whether they are published or not. The documents may come from teaching and research institutions in France or abroad, or from public or private research centers.
L'archive ouverte pluridisciplinaire HAL, est destinée au dépôt et à la diffusion de documents scientifiques de niveau recherche, publiés ou non, émanant des établissements d'enseignement et de recherche français ou étrangers, des laboratoires publics ou privés. 
2 European Journal of Clinical Microbiology \& Infectious Diseases

Manuscript No. EJCM-D-20-01026 R1

4

Brief report

9 landreoletti@chu-reims.fr.

Chad

\section{Words}

${ }^{1}$ Institut National de Recherche en Santé Publique, Bamako, Mali

${ }^{2}$ Service de Maladies infectieuses, Hôpital Le Bon Samaritain, CHU Walia, N’Djamena,

${ }^{3}$ Service de Médecine interne, Maladies infectieuses et Immunologie Clinique, Hôpital Robert Debré, CHU Reims, France

${ }^{4}$ Laboratoire de Virologie médicale et moléculaire, Hôpital Robert Debré CHU Reims \& EA4684, Faculté de Médecine, Université Reims Champagne Ardennes, Reims, France

${ }^{5}$ EA 3064, Faculté de Médecine, Université Jean Monnet, Saint-Etienne, France.

* Corresponding author: Tel: +33 326783993; Fax: +33 326784134; E-mail: 


\section{Abstract: (98 words)}

2 Purpose: No data concerning Anti-Retroviral drugs (ARV) primary resistance mutation rates

3 in Chad are available.

4 Methods: We retrospectively analysed frozen-stored dried blood spot samples that were 5 collected from 48 Chadian Human Immunodeficiency Virus (HIV)-1 seropositive patients 6 naïve of ARV.

7 Results: HIV-1 protease and reverse transcriptase genes were successfully sequenced for 24 $8(60.0 \%)$ of the 40 patients displaying a viral load $>1000$ copies $/ \mathrm{ml}$. Seven $(29.2 \%)$ displayed 9 mutations conferring resistance against one or more classes of ARV.

10 Conclusion: We evidenced high levels of primary ARV resistance mutations in Chad, 11 but lower than those observed in patients with failure to first-line ARV.

14 Keywords: HIV; Chad; Non-Nucleoside Reverse Transcriptase Inhibitor; primary resistance. 
Introduction:

Access to Highly Active Antiretroviral drugs (ARV) has significantly reduced Human Immunodeficiency Virus (HIV) transmission in sub-Saharan African countries which still support the highest burden of the pandemic [1]. However in these countries, access to free but discontinuous first-line antiretroviral regimens consisting almost exclusively of Nucleoside Reverse Transcriptase Inhibitors (NRTI) combined with a Non Nucleoside Reverse Transcriptase Inhibitors (NNRTI) with low genetic barrier to resistance could rapidly lead to the emergence of antiretroviral drugs resistance among ARV-treated patients. In lowincome countries of sub-Saharan Africa, monitoring of HIV plasma viral load that is recommended by World Health Organization (WHO) since 2013 and genotyping tests allowing the detection of HIV strains harbouring resistance mutations to antiretroviral drugs are not continuously available. Horizontal or vertical transmission levels of such HIV strains harbouring major resistance mutations to NNRTIs or NRTIs represent a major public health problem and may significantly impact subsequent choices of antiretroviral drugs regimen for newly HIV infected patients in sub-Saharan African countries.

Located in Central Africa, Chad had an estimated HIV seroprevalence of $1.3 \%$ among the sexually active population (15-49 years) and ranked fifth in terms of HIV mortality rate (71 per 1000) [2,3]. Moreover, Chad is partly bordered by Cameroon, where a wide diversity of HIV strains has been evidenced [4]. Thus, Chadian HIV strains could present a great viral genetic diversity including non $\mathrm{M}$ variants of HIV-1, group $\mathrm{M}$ non B subtypes or recombinant strains potentially carrying mutations conferring resistance to antiretroviral drugs used as first or second lines of treatment $[5,6]$. Only two previous investigations reported high rates of viral mutations conferring resistance to antiretroviral drugs in Chadian patients with virological failure [5,6]. To date, no published data concerning ARV primary resistance 
1 mutation rates in Chad are available. In the present report, we retrospectively investigated

2 frozen dried blood spot (DBS) samples from HIV-1 Chadian patients who were naïve of ARV.

\section{Patients and methods}

5 From August to November 2012, 48 successive newly HIV-1 seropositive adult patients who

6 were naïve of any ARV treatment (30 F/18 M, median age 32years [18-52]) and who were

7 attending to the chronic diseases centre of the hospital "le Bon Samaritain" (N'Djamena,

8 Chad) were enrolled in the present investigation. World Health Organization HIV disease

9 Clinical stage has been defined elsewhere [7]. Median Lymphocytes T-CD4 cells count

10 performed on FACS $®$ count system was 273 cells per mm3 [13 - 1049] for these 48 patients.

11 An oral informed consent for medical research investigations was obtained from each study

12 patient and if needed from their relative family members. This study was approved by local

13 ethics committee. For each patient, blood samples were collected before ARV and sent abroad

14 ("Université" Jean Monnet, Saint-Etienne, and "Université" Reims Champagne Ardennes,

15 France) as dried blood spots (DBS) after approximately one month of storage at room

16 temperature [8,9]. Each DBS sample was then stored at $-80^{\circ} \mathrm{C}$ until performing HIV-RNA

17 viral load and genotyping assays in France according to previously described protocols $[8,9]$.

18 Protease gene and reverse transcriptase gene region were fully covered by sequencing

19 analysis and obtained sequences were compared against referenced subtype B HBX-2 strain

20 (Genbank accession number: K03455.1). All of our HIV-1 sequences were submitted to the

21 Genbank and obtained an original accession number (Table 1).Concerning drug resistance

22 mutations, interpretation of sequencing results was performed according to the French

23 National Agency for AIDS Research resistance algorithm [10]. HIV-1 subtypes were

24 established using the Stanford HIV database and Sierra version 1.1 HIVdb 8.1.1 [11].

25 Quantitative variables were compared using the Mann Whitney U-test and qualitative 
variables were compared using Pearson's Chi-square test. Statistical analyses were performed

2 using Stat view 5.0 software (SAS institute).

\section{Results}

Following RNA extraction from DBS [8], median HIV-1 viral load was estimated to $4.72 \log$ copies/ml [3.24- 5.95] for $40(83.3 \%)$ out of the 48 study patients with a detected viral load upper than 1000 HIV-RNA copies per ml. HIV-1 protease and reverse transcriptase genes were successfully amplified and sequenced for only $24(60.0 \%)$ of the 40 patients with a detectable viral load (Table 1). Median HIV-1 viral load and median CD4 cells counts were respectively statistically higher and lower in patients who had successful sequences than in those that did not (Table 2).

Interestingly, 7 (29.2\%) of the 24 successfully sequenced DBS samples exhibited referenced nucleotide mutations conferring HIV-1-resistance against at least one antiretroviral drug. The most frequently detected mutation was the V106I (20.8\%) described as a natural polymorphism in HIV-1 non-B subtypes and conferring resistance to etravirine when it is associated to at least one other mutation, according to French National Agency for AIDS Research resistance algorithm [9]. The K103N mutation that confers complete resistance to efavirenz and nevirapine was found in 2 subjects (8.3\%) out of the 24 . One K65E and one V179D were also detected in two distinct individuals conferring resistance to tenofovir and rilpivirine, respectively. The L90M major protease inhibitor resistance mutation was found in 21 one patient (4.1\%). Polymorphic mutations (L10I, G16E, K20I, M36I, I62V, V77I, L89M) were evidenced in 21 sequences $(87.5 \%)$. HIV-1 protease sequences predicting phenotypic resistance to saquinavir and a combined resistance to nelfinavir, indinavir and atazanavir were evidenced in 3 patients (12.5\%). 
The most prevalent HIV-1 subtype was Circulating Recombinant Form (CRF)

2 CRF11_CPX subtype and was identified in 7 of the 24 samples $(29,2 \%)$. Others previously described HIV recombinant forms accounted for 8 out of the 24 samples (33.3\%) (Table 1).

All patients were treated by NRTI plus first generation NNRTI (such as efavirenz or nevirapine). Among these 24 patients, 4 died (16.6\%) (None among those with mutations leading to resistance or possible resistance to NNRTI), and 14 (58.3\%) were lost to follow-up which is consistent with the high attrition rates previously observed in Chad [12].

\section{Discussion}

In the present report we retrospectively analysed frozen-stored DBS sampled from a series of HIV-1 seropositive patients who were naïve of Highly Active Antiretroviral drugs (ARV) and were living in Chad (Ndjamena), 2012. All of these patients were newly HIV1diagnosed and were sampled before initiation of ARV consisting of NRTI and NNRTI combination. We evidenced a CRF11_CPX HIV subtype predominance in accordance with a previously published investigation on Chadian HIV-1 infected patients [5]. Because this previous study focused only patients with detectable viral loads after 6 months of ARV, the reported rates of mutations conferring resistance to at least one antiretroviral drug was high and estimated to $64 \%$ [5]. In 2018 Keita et al. observed in plasma samples from newly HIVdiagnosed Malian patients a significant increase of the ARV primary resistance mutation rates evolving from $7.8 \%$ in 2010 to $17.5 \%$ in 2014 , especially mutations conferring resistance to NNRTI like K103N mutation or other natural polymorphic mutations conferring resistance or potential resistance to etravirine, another NNRTI drug not yet currently used in Mali [8]. In the present retrospective monocentric study including a limited series of patients, we showed for the first time high rates of similar ARV primary resistance mutations (29.2\%) in Chad, 
1 whose levels were lower than those previously observed in Chadian patients (36-64\%)

2 displaying a failure to first-line ARV regimen $[5,6]$.

3

Our HIV genotyping results could be due to the combined presence of viral RNA and DNA in DBS and the detection of archived mutations currently not detectable by classical genotypic test on plasma RNA. It has been shown that high levels of HIV-1 DNA can induce falsely positive results for the detection of HIV-RNA resistance mutations in about $35 \%$ of cases on DBS [13]. However, even if genotyping assays efficiency declined after DBS storage at room temperature [14], the use of DBS offers the advantage of a stable and easy to be transported samples with a minimal biohazard risk. Moreover, sending collected blood samples abroad as DBS for further genotyping analysis could be the most reliable way to monitor resistance to antiretroviral drugs because of recurrent blackouts and material/reagent stockouts in low-income countries such as Chad [5,6]. Samples to send abroad could be randomly selected in case of global monitoring of circulation of strains harbouring resistance or individually selected in suspected virological failure cases. In the absence of available HIV-1 RNA load monitoring for each patient, absence of rise of lymphocyte T-CD4 count under ARV is commonly used as a proxy for virological failure in central Africa. In this situation, first line ARV using NRTI plus NNRTI combination is empirically switched to a second line treatment with Protease Inhibitor without waiting for of HIV RNA load results or genotyping analysis performed abroad.

Taking into account the few previous published Sahelian reports and our present original results, we suggest that free-access to new cheap antiretroviral drugs with high genetic barrier to resistance should be prioritized over any implementation strategy of HIV genotyping assays in low-income central Africa countries such as Mali or Chad. Dolutegravir containing regimen could be a good candidate for new first-line ARV regimen in these low- 
1 income countries, it could be used in association with rifampin and first line anti-tuberculous

2 agents as well as in pregnant women [15]. Dolutegravir containing regimen is now 3 recommended by WHO [15], but to date this ARV drug is not yet in full free-access for the 4 population of Chad.

5

6

7

8

9

10

11

12

Acknowledgements: We thank Abbott for its support by providing us HIV genotyping kits.We are indebted to Mrs Veronique Sauron and Audrey Jasserand for excellent technical assistance.

Funding: this work was supported by grants from INRPS (Bamako Mali) and by local grants from University Champagne Ardenne (URCA, France), University Jean Monnet (St Etienne, France).

Conflicts of interest/Competing interests: none to declare

Ethics approval: not required in this non interventional study

Consent to participate: all patients were informed of the study and gave oral consent for the analysis of their samples abroad.

\section{References:}

1. HIV/AIDS Key facts. https://www.who.int/news-room/fact-sheets/detail/hiv-aids

2. UNAIDS. Prevalence of HIV, total (\% of population ages 15-49) https://data.worldbank.org/indicator/SH.DYN.AIDS.ZS?end=2016\&name_desc=false\&start= $1990 \&$ view=chart 
1 3. Granich R, Gupta S, Hersh B et al. Trends in AIDS Deaths, New Infections and ART

2 Coverage in the Top 30 Countries with the Highest AIDS Mortality Burden; 1990-2013.

$3 \quad$ PLoS ONE. 2015;10:e0131353

4 4. Courtney CR, Agyingi L, Fokou A et al. Monitoring HIV-1 Group M Subtypes in Yaoundé, 5 Cameroon Reveals Broad Genetic Diversity and a Novel CRF02_AG/F2 Infection. AIDS Res

6 Hum Retroviruses. 2016; $32: 381-5$.

7 5. Koyalta D, Charpentier C, Beassamda J et al. High frequency of antiretroviral drug 8 resistance among HIV-infected adults receiving first-line highly active antiretroviral therapy 9 in N'Djamena, Chad.Clin Infect Dis. 2009; $49: 155-9$.

10 6. Adawaye C, Fokam J, Kamangu E et al. Virological Response, HIV-1 Drug Resistance 11 Mutations and Genetic Diversity Among Patients on First-Line Antiretroviral Therapy in

12 N'Djamena, Chad: Findings From a Cross-Sectional Study. BMC Res Notes . 2017 ; 10:589.

14 and children.

15 https://www.who.int/hiv/pub/guidelines/arv2013/annexes/WHO_CG_annex_1.pdf?ua=1

8. Keita A, Sereme Y, Pillet S et al. Impact of HIV-1 primary drug resistance on the efficacy

17 of a first-line antiretroviral regimen in the blood of newly diagnosed individuals in Bamako,

18 Mali. J Antimicrob Chemother. 2019; $74: 165-71$.

9. Mbida AD, Sosso S, Flori P et al. Measure of viral load by using the Abbott Real-Time HIV-1 assay on dried blood and plasma spot specimens collected in 2 rural dispensaries in

21 Cameroon. J Acquir Immune Defic Syndr. 2009; 52 : 9-16. 
1 10. French National Agency for AIDS Research. Table of rules HIV1.

2 http://www.hivfrenchresistance.org/

3 11. Stanford University HIV Drug Resistance Database. HIV Subtyping program.

4 http://www.hiv.db.stanford.edu/page/hiv-subtyper/

5 12. Djarma O, Nguyen $Y$, Renois $F$ et al. Continuous free access to HAART could be one of

6 the potential factors impacting on loss to follow-up in HAART-eligible patients living in a

7 resource-limited setting: N'djamena, Chad. Trans R Soc Trop Med Hyg. 2014; 108 : 735-8.

8 13. Zida $S$, Tuaillon E, Barro $M$ et al. Estimation of HIV-1 DNA Level Interfering With

9 Reliability of HIV-1 RNA Quantification Performed on Dried Blood Spots Collected From

10 Successfully Treated Patients. J Clin Microbiol . 2016;54:1641-1643.

11 14. García-Lerma JG, McNulty A, Jennings C, et al. Rapid decline in the efficiency of HIV

12 drug resistance genotyping from dried blood spots (DBS) and dried plasma spots (DPS)

13 stored at 37 degrees C and high humidity. J Antimicrob Chemother. 2009;64:33-6.

14 15. World Health Organisation. Update of recommendations on first- and second-line

15 antiretroviral regimens. https://www.who.int/hiv/pub/arv/arv-update-2019-policy/en/ 
1 Table caption:

2 Table 1: Virological data obtained from frozen-stored dried blood spot samples of 24

3 Chadian HIV-1 seropositive patients naïve of Highly Active Antiretroviral Drugs (ARV).

4 


\begin{tabular}{|c|c|c|c|c|c|c|c|}
\hline $\begin{array}{l}\text { Patient } \\
\text { number }\end{array}$ & $\begin{array}{c}\text { Viral } \\
\text { load } \\
(\log / \mathrm{mL})\end{array}$ & $\begin{array}{l}\text { HIV-1 } \\
\text { subtype }\end{array}$ & $\begin{array}{c}\text { Protease } \\
\text { gene } \\
\text { mutations }\end{array}$ & $\begin{array}{c}\text { Reverse } \\
\text { transcriptase } \\
\text { gene mutations }\end{array}$ & $\begin{array}{c}\text { Drug } \\
\text { resistance }\end{array}$ & $\begin{array}{c}\text { Possible } \\
\text { Drug } \\
\text { resistance }\end{array}$ & $\begin{array}{l}\text { Genbank } \\
\text { reference }\end{array}$ \\
\hline 1 & 4.57 & CRF11_CPX & I62V, V77I & & & & MW250374 \\
\hline 2 & 4.44 & B & & $\begin{array}{c}\text { K65E, V75E, } \\
\text { I135V, M164L, } \\
\text { I178M }\end{array}$ & & TDF & MW250369 \\
\hline 3 & 3.82 & CRF11_CPX & G16E, V77I & & & & MW250377 \\
\hline 4 & 4.71 & G & & $\begin{array}{l}\text { K73EQ, K122P, } \\
\text { I142V, K173T, } \\
\text { Q174K, D177E, } \\
\text { E174D, V292I, } \\
\text { D324E, I329V }\end{array}$ & & & MW250370 \\
\hline 5 & 4.28 & CRF45_CPX & $\begin{array}{c}\text { K20I, L24F, } \\
\text { M36I, } \\
\text { L89M }\end{array}$ & $\begin{array}{l}\text { L74H, V179D, } \\
\text { K238N, V179D }\end{array}$ & & $\begin{array}{l}\text { RPV, } \\
\text { EFV, } \\
\text { NVP }\end{array}$ & $\begin{array}{l}\text { MW250372 } \\
\text { (P) } \\
\text { MW250373 } \\
\text { (RT) }\end{array}$ \\
\hline 6 & 4.37 & A1 & $\begin{array}{c}\text { L90M, } \\
\text { L10I, M36I, } \\
\text { L89M }\end{array}$ & & NFV & $\begin{array}{c}\text { SQV, } \\
\text { IDV, ATV }\end{array}$ & MW250375 \\
\hline 7 & 4.02 & CRF13_CPX & $\begin{array}{l}\text { K20I, M36I, } \\
\text { V77I, I50N }\end{array}$ & & & & MW250376 \\
\hline 8 & 5.26 & CRF11_CPX & $\begin{array}{l}\text { L10I, M36I, } \\
\text { V77I, L89M }\end{array}$ & & & & MW250371 \\
\hline 9 & 4.78 & CRF11_CPX & $\begin{array}{l}\text { L10I, M36I, } \\
\text { V77I, L89M }\end{array}$ & & & & MW250353 \\
\hline 10 & 3.63 & D & $\begin{array}{l}\text { K20R, } \\
\text { M36I }\end{array}$ & V106I & & & MW250354 \\
\hline 11 & 4.61 & CRF45_CPX & K20X, & & & & MW250356 \\
\hline
\end{tabular}




\begin{tabular}{|c|c|c|c|c|c|c|c|}
\hline & & & $\begin{array}{l}\text { M36I, } \\
\text { L89M }\end{array}$ & & & & \\
\hline 12 & 5.36 & D & $\begin{array}{l}\text { K20I, M36I, } \\
\text { V77I, L89M }\end{array}$ & V106I & & & MW250355 \\
\hline 13 & 4.73 & CRF45_CPX & $\begin{array}{c}\text { L10I, K20I, } \\
\text { M36I, } \\
\text { L89M }\end{array}$ & & & SQV & MW250357 \\
\hline 14 & 4.99 & CRF13_CPX & $\begin{array}{c}\text { K20I, M36I, } \\
\text { L89M }\end{array}$ & V106I & & & MW250358 \\
\hline 15 & 4.97 & D & M36I, I62V & V106I & & & MW250359 \\
\hline 16 & 5.79 & D & K20R, M61 & V106I & & & MW250360 \\
\hline 17 & 5.70 & D.G & $\begin{array}{l}\text { K20I, M36I, } \\
\text { I62V, L89M }\end{array}$ & & & SQV & MW250361 \\
\hline 18 & 5.43 & G & & & & & MW250368 \\
\hline 19 & 5.75 & CRF11_CPX & $\begin{array}{c}\text { I62V, V77I, } \\
\text { L89I }\end{array}$ & & & & MW250362 \\
\hline 20 & 5.56 & CRF02_AG & $\begin{array}{c}\text { K20I, M36I, } \\
\text { L89M }\end{array}$ & K103N & $\begin{array}{l}\text { EFV, } \\
\text { NVP }\end{array}$ & & MW250363 \\
\hline 21 & 5.47 & CRF11_CPX & I62V, V77I & & & & MW250364 \\
\hline 22 & 4.38 & CRF13_CPX & $\begin{array}{c}\text { K20I, M36I, } \\
\text { V77I }\end{array}$ & & & & MW250365 \\
\hline 23 & 5.49 & CRF02_AG & $\begin{array}{c}\text { K20I, M36I, } \\
\text { L63P, } \\
\text { L89M }\end{array}$ & & & & MW250366 \\
\hline 24 & 5.95 & CRF11_CPX & I62V, V77I & K103N & $\begin{array}{l}\text { EFV, } \\
\text { NVP }\end{array}$ & & MW250367 \\
\hline
\end{tabular}


Table 2 : Differences between patients with successfully amplified sequences than those

without. * The 8 patients with indetectable viral load were considered as missing data among the viral loads of patients without successfully amplified sequences.

\begin{tabular}{|l|l|l|l|}
\hline & Patients with successfully & Patients without & P \\
& amplified sequences & successfully amplified & \\
\hline Male sex (n\%) & $11(45.80)$ & $7(29.10)$ & \\
\hline Median Age [range] (years) & $33[20-45]$ & $30[18-52]$ & 0.23 \\
\hline Median World Health & $3[1-4]$ & $2[1-4]$ & 0.15 \\
Organization HIV disease & & & \\
\hline Clinical stage [range] & & $415[13-918]$ & \\
\hline Median CD4 Cells counts & $230[22-1049]$ & & 0.01 \\
\hline [range] (/mm3) & & $4.03[3.24-4.99]^{*}$ & 0.003 \\
\hline Median viral load [range] & $4.87[3.63-5.95]$ & & \\
\hline (log copies/ml) & & & \\
\hline
\end{tabular}

